\title{
Characterization of High Fludioxonil Resistance in Botrytis cinerea Isolates from Calibrachoa Flowers
}

\author{
Madeline Dowling, ${ }^{1}$ Jhulia Gelain, ${ }^{2}$ Louise Larissa May De Mio, ${ }^{2}$ and Guido Schnabel1,† \\ ${ }^{1}$ Department of Plant and Environmental Sciences, Clemson University, Clemson, SC 29634, U.S.A.
}

${ }^{2}$ Department of Plant Sciences, Universidade Federal do Paraná, Curitiba, Brazil

Accepted for publication 8 October 2020.

\begin{abstract}
The fungicide fludioxonil is one of the most effective single-site fungicides available for managing flower blight caused by Botrytis cinerea on fruit and ornamental crops. Although low and moderate levels of resistance to fludioxonil have been reported in the pathogen across the United States and Europe, high resistance has been reported only from greenhouses in China. In this study, two $B$. cinerea isolates with high resistance (half maximal effective concentration $>100 \mu \mathrm{g} / \mathrm{ml}$ ) to fludioxonil were detected on ornamental calibrachoa flowers grown in a greenhouse. These isolates exhibited stable resistance for $>20$ generations, produced symptoms on calibrachoa flowers sprayed with label rates of fludioxonil, and displayed in vitro fitness penalties with decreased mycelial growth $(P<0.0001)$ and sporulation $(P<0.0001)$
\end{abstract}

ABSTRACT

The phenylpyrrole fungicide fludioxonil is an important mainstay for managing diseases caused by Botrytis cinerea on both ornamental and food crops before and after harvest (Förster et al. 2007; Rupp et al. 2017). Fludioxonil currently combines fungicidal efficacy with limited resistance development (Fernández-Ortuño et al. 2014; Kim et al. 2016; Petit et al. 2011; Rupp et al. 2017). This combination is particularly important considering the widespread resistance of $B$. cinerea to most major chemical classes, with some isolates having simultaneous resistance to seven chemical classes (Cosseboom et al. 2019; Fernández-Ortuño et al. 2014, 2015).

Fludioxonil's mode of action has not been fully delineated (Kilani and Fillinger 2016; Li et al. 2014). However, exposure to fludioxonil is associated with the activation of the highosmolarity glycerol (HOG1) mitogen activated protein kinase (MAPK) pathway (Furukawa et al. 2012; Zhang et al. 2002). This pathway includes a two-component regulatory system composed of the sensor kinase, OS-1, which detects osmotic stress conditions, and a response regulator that receives signals from OS- 1 and adjusts gene expression to regulate the cell's response to osmotic stress (Furukawa et al. 2012; Viaud et al. 2006). Fludioxonil is believed to mimic an osmotic stress signal by binding to OS-1, triggering inappropriate activation, which results in overaccumulation of glycerol, ion fluxes, and abnormally high turgor pressure (Lew 2010; Zhang et al. 2002). Fungi exposed to fludioxonil often exhibit swollen

†Corresponding author: G. Schnabel; schnabe@clemson.edu

Funding: Technical contribution number 6899 of the Clemson University Experiment Station. This material is based on work supported by NIFA/USDA, under project number SC-1700530.

*The $\boldsymbol{e}$-Xtra logo stands for "electronic extra" and indicates that two supplementary figures are published online.

The author(s) declare no conflict of interest.

(c) 2021 The American Phytopathological Society compared with sensitive isolates. Highly resistant isolates were identified as MDR1h, containing the $\Delta \mathrm{L} / \mathrm{V} 497$ deletion in $m r r l$. However, resistance levels and in vitro fitness parameter characteristics were not consistent with this phenotype. One isolate contained the mutation L267V between HAMP domains 1 and 2 of the Bos- 1 gene, and both isolates exhibited high osmotic sensitivity and reduced glycerol accumulation in the presence of fludioxonil, indicating that high resistance of these isolates may be associated with the high-osmolarity glycerol mitogen-activated protein kinase pathway.

Keywords: antimicrobial or fungicide resistance, chemical control, disease control and pest management

hyphae with ruptured apexes, indicating that this increased turgor pressure ultimately leads to cell lysis and death (Leroux 1996; Zhang et al. 2002).

Few documented instances of fungal isolates highly resistant (HR) to fludioxonil in the field have occurred to date (Kilani and Fillinger 2016). Most of these instances occurred in Alternaria spp., where high resistance to fludioxonil (half maximal effective concentration $\left[\mathrm{EC}_{50}>10\right] \mu \mathrm{g} / \mathrm{ml}$ ) has been reported in Europe and the United States (Avenot and Michailides 2015; Malandrakis et al. 2015). In one case, dual fludioxonil- and iprodione-resistant isolates made up $14 \%$ of a population (Malandrakis et al. 2015). For B. cinerea, fludioxonil HR isolates $\left(\mathrm{EC}_{50}>5 \mu \mathrm{g} / \mathrm{ml}\right)$ have never been reported in the field but have been documented from greenhouses in China on strawberry, cucumber, and tomato (Ren et al. 2016; Sang et al. 2018; Zhou et al. 2020). In one analysis in China, HR isolates made up $<3 \%$ of the Botrytis population from greenhouses included in the study (Ren et al. 2016). Mutations were detected in HR $B$. cinerea isolates in the HAMP domains of the $O S-1$ gene, called Bos- 1 in B. cinerea, and some of these isolates were cross-resistant to dicarboximide fungicides (Ren et al. 2016). Generally, both laboratory and greenhouse HR isolates exhibited fitness penalties affecting sporulation and osmotic sensitivity (Ren et al. 2016; Sang et al. 2018; Zhou et al. 2020). To the best of our knowledge, high resistance to fludioxonil has not been reported outside China for B. cinerea on any crop.

Although $B$. cinerea isolates highly resistant to fludioxonil are rarely found in the field, low and moderately resistant isolates of $B$. cinerea are often detected in ornamental flower greenhouses, strawberry fields, and vineyards in the United States and Europe (Cosseboom et al. 2019; Fernández-Ortuño et al. 2014; Kretschmer et al. 2009; Leroch et al. 2011, 2012; Li et al. 2014; Rupp et al. 2017). This resistance is not specific to fludioxonil but is drug efflux based multidrug resistance (MDR) associated with overexpression of the ABC transporter AtrB. This pump is regulated by the transcription factor mrrl, and mutations in the $\mathrm{mrrl}$ gene result in two main phenotypes: MDR1, conferring low resistance, and 
MDR1h, conferring moderate resistance to fludioxonil (Hahn 2014) (Table 1).

While performing a Botrytis resistance monitoring program in 2019, we detected two isolates with abnormally high resistance to fludioxonil. The goal of this study was to characterize these isolates by investigating the level of resistance to fludioxonil and the dicarboximide fungicide iprodione, the stability of resistance, the field relevance of this resistance, the potential molecular sources of resistance, and the fitness of resistant isolates.

\section{MATERIALS AND METHODS}

Fungal isolates and culture conditions. B. cinerea spores were collected on sample swabs from infected calibrachoa leaf tissue in a commercial greenhouse in North Carolina. The plants had developed gray mold disease despite routine fungicide applications. Spores were transferred to media amended with discriminatory dosages of fungicides as described previously (Fernández-Ortuño et al. 2014). Based on their abnormally rapid mycelial growth on a $0.5 \mu \mathrm{g} / \mathrm{ml}$ discriminatory dose of fludioxonil, samples 5.8.19 and 5.10.19 were stored. For isolation, spores were transferred to malt extract agar (MEA) plates amended with $100 \mu \mathrm{g} /$ $\mathrm{ml}$ fludioxonil to distinguish resistant spores. Spore cultures were incubated in the dark at $22^{\circ} \mathrm{C}$ for approximately $24 \mathrm{~h}$. Individual germinating spores were then transferred to new MEA amended with $100 \mu \mathrm{g} / \mathrm{ml}$ fludioxonil to ensure collection of only highly resistant isolates (Table 2).

For comparison, three previously characterized Botrytis isolates from strawberry (Fernández-Ortuño et al. 2015) were revived (HP9, NC4, and FLOR5). These isolates were sensitive (S) to fludioxonil (no growth at $0.5 \mu \mathrm{g} / \mathrm{ml}$ ) and iprodione $(10 \mu \mathrm{g} / \mathrm{ml})$ discriminatory dosages (Table 2).

Characterization of sensitivity to fludioxonil and iprodione. To characterize fludioxonil and iprodione resistance, spore germination and mycelial growth were tested for isolates 5.8.19 and 5.10.19
(HR). For spore germination, 15- to 20-day-old cultures sporulating on 90-mm Petri dishes containing approximately $15 \mathrm{ml}$ of MEA were washed with deionized sterile water, and the spore concentration adjusted to $3 \times 10^{5}$ spores $/ \mathrm{ml}$. Then $50 \mu \mathrm{l}$ of this spore suspension was spread onto fungicide amended plates with a Drigalski spatula, and cultures were incubated $24 \mathrm{~h}$ at $22^{\circ} \mathrm{C}$ in the dark. For mycelial growth, 5-mm plugs were transferred from the margins of 3- to 5-day-old cultures to fungicide amended media and colony diameters measured after 2 days of incubation at $22^{\circ} \mathrm{C}$ in the dark. Both mycelial growth and spore germination tests were performed on MEA and potato dextrose agar (PDA) either unamended or amended with $100 \mu \mathrm{g} / \mathrm{ml}$ fludioxonil (Scholar; Syngenta, Greensboro, NC) and $100 \mu \mathrm{g} / \mathrm{ml}$ iprodione (Rovral; BayerCrop Science, Research Triangle Park, NC). Three replicate plates were used for each fungicide concentration and medium type, and the experiment was conducted twice.

The isolates' stability of resistance to fludioxonil and iprodione was determined by transferring them 22 times on unamended MEA. The 5-mm plugs were transferred from colony margins every 2 to 3 days. Resistance of isolates in storage was also analyzed for isolates incubated in the dark at $22^{\circ} \mathrm{C}$ for 3 months and transferred once each month. For both tests, after the final transfer, isolates were transferred to plates amended with $100 \mu \mathrm{g} / \mathrm{ml}$ of fludioxonil and $100 \mu \mathrm{g} / \mathrm{ml}$ of iprodione to detect any loss of resistance.

DNA extraction, amplification, and sequencing Bos-1 and $\mathbf{m r r} 1$ genes. Because the Botrytis cinerea $O S-1$ (Bos-1) and the multidrug resistance regulator transcription factor ( $m r r l)$ genes have both been associated with fludioxonil resistance, their sequences were analyzed for potential resistance mutations in HR isolates. DNA was extracted according to the protocol by Chi et al. (2009).

The complete Bos- 1 gene was amplified with the primer pairs $\mathrm{BF} 1 / \mathrm{BR} 1, \mathrm{BF} 2 / \mathrm{BR} 2, \mathrm{BF} 3 / \mathrm{BR} 3, \mathrm{BF} 4 / \mathrm{BR} 4$, and BF5/BR5, described by Ma et al. (2007). Amplification was performed with the following parameters: initial denaturation at $95^{\circ} \mathrm{C}$ for $3 \mathrm{~min}$,

TABLE 1. Comparison of traits for isolates resistant or sensitive to fludioxonil from this study and previous literature reports ${ }^{\mathrm{z}}$

\begin{tabular}{|c|c|c|c|c|c|c|c|}
\hline \multirow[b]{3}{*}{ Literature } & \multirow[b]{3}{*}{ Host } & \multicolumn{2}{|c|}{ Phenylpyrrole } & \multicolumn{2}{|c|}{ Dicarboximide } & \multirow{2}{*}{\multicolumn{2}{|c|}{ Amino acid alterations }} \\
\hline & & \multirow[b]{2}{*}{ Phenotype } & \multirow{2}{*}{$\begin{array}{c}\mathrm{EC}_{50} \\
(\mu \mathrm{g} / \mathrm{ml})\end{array}$} & \multirow[b]{2}{*}{ Phenotype } & \multirow{2}{*}{$\begin{array}{c}\mathrm{EC}_{50} \\
(\mu \mathrm{g} / \mathrm{ml})\end{array}$} & & \\
\hline & & & & & & Bos 1 & $m r r 1$ \\
\hline Current study & $\begin{array}{l}\text { Calibrachoa } \\
\text { (greenhouse) }\end{array}$ & HR (MDR1h) & $>100$ & HR & $>100$ & F127S, I365N, L267V & $\Delta \mathrm{L} / \mathrm{V} 497$ \\
\hline Ren et al. 2016 & $\begin{array}{l}\text { Strawberry, } \\
\text { cucumber } \\
\text { (greenhouse) }\end{array}$ & HR & $>100$ & HR & $>100$ & $\begin{array}{c}\text { F127S, G262S, G265D, G311R, } \\
\text { R319K, V336M, D337N, V346I, } \\
\text { A350S, I365N, Q369P, N373S, } \\
\text { S426P, G538R, G545E, N609T, } \\
\text { A1259T }\end{array}$ & n.d. \\
\hline \multirow{4}{*}{$\begin{array}{l}\text { Fernández-Ortuño et al. } \\
\text { 2015; Hu et al. } 2019 \text {; } \\
\text { Grabke et al. } 2014\end{array}$} & Strawberry (field) & MR (MDR1h) & $0.5-3.1$ & n.d. & n.d. & n.d. & $\Delta \mathrm{L} / \mathrm{V} 497$ \\
\hline & Strawberry (field) & LR (MDR1) & $0.1-0.5$ & n.d. & n.d. & n.d. & $\begin{array}{c}\text { R351C, D354Y, } \\
\text { G702N }\end{array}$ \\
\hline & Strawberry (field) & $\mathrm{S}$ & $0-0.1$ & MR-HR & $4.7->100$ & F127S, I365N & None, $\Delta \mathrm{L} / \mathrm{V} 497$ \\
\hline & Strawberry (field) & $\mathrm{S}$ & $0-0.1$ & n.d. & n.d. & n.d. & None \\
\hline
\end{tabular}

${ }^{\mathrm{z}} \mathrm{EC}_{50}$, half maximal effective concentration; HR, highly resistant; LR, low resistant; MR, moderately resistant; n.d., data not determined; S, sensitive.

TABLE 2. Name, origin, host, fludioxonil resistance phenotype, amino acid alterations, and source of isolates used in this study

\begin{tabular}{|c|c|c|c|c|c|c|}
\hline \multirow[b]{2}{*}{ Isolate name } & \multirow[b]{2}{*}{ Origin } & \multirow[b]{2}{*}{ Host } & \multirow[b]{2}{*}{ Fludioxonil phenotype ${ }^{z}$} & \multicolumn{2}{|c|}{ Amino acid alterations } & \multirow[b]{2}{*}{ Source } \\
\hline & & & & Bos -1 & $m r r 1$ & \\
\hline 5.8 .19 & North Carolina & Calibrachoa & HR & F127S, L267V, I365N & $\Delta \mathrm{L} / \mathrm{V} 497$ & This study \\
\hline 5.10 .19 & North Carolina & Calibrachoa & HR & $\mathrm{F} 127 \mathrm{~S}, \mathrm{I} 365 \mathrm{~N}$ & $\Delta \mathrm{L} / \mathrm{V} 497$ & \\
\hline FLOR5 & South Carolina & Strawberry & $\mathrm{S}$ & None & None & Fernández-Ortuño et al. 2015 \\
\hline HP9 & North Carolina & Strawberry & $\mathrm{S}$ & None & None & \\
\hline $\mathrm{NC} 4$ & North Carolina & Strawberry & $\mathrm{S}$ & None & None & \\
\hline UGA1 & Georgia & Blackberry & MR & $\mathrm{I} 365 \mathrm{~S}$ & $\Delta \mathrm{L} / \mathrm{V} 497$ & \\
\hline
\end{tabular}

${ }^{\mathrm{z}}$ HR, highly resistant; MR, moderately resistant; S, sensitive. 
followed by 40 cycles at $94^{\circ} \mathrm{C}$ for $1 \mathrm{~min}, 60^{\circ} \mathrm{C}$ for $1 \mathrm{~min}$, and $72^{\circ} \mathrm{C}$ for $1 \mathrm{~min}$ and $30 \mathrm{~s}$, with final elongation at $72^{\circ} \mathrm{C}$ for $5 \mathrm{~min}$.

The majority of the $\mathrm{mrrl}$ gene was amplified with primer pairs MRR1_atg/TF1-2-new and TF1-3/TF1-4 (Leroch et al. 2012). The amplification protocol consisted of an initial denaturation at $94^{\circ} \mathrm{C}$ for $5 \mathrm{~min}$, followed by 40 cycles of $94^{\circ} \mathrm{C}$ for $30 \mathrm{~s}, 50^{\circ} \mathrm{C}$ for $1 \mathrm{~min}$, and $72^{\circ} \mathrm{C}$ for $2 \mathrm{~min}$, with a final elongation at $72^{\circ} \mathrm{C}$ for $10 \mathrm{~min}$.

PCR products were purified and sequenced by Arizona State University Core Laboratories. Resulting DNA sequences were aligned and translated, and then translations were aligned in SEQman Pro, SEQbuilder Pro (DNASTAR, Inc., Madison, WI), and MEGA7 (Kumar et al. 2016), respectively.

Mycelium osmotic sensitivity determination. To determine whether fludioxonil resistance in HR isolates resulted in higher sensitivity to osmotic stress, $\mathrm{S}$ and HR isolates were grown on PDA for 3 to 5 days. Then $5 \mathrm{~mm}$ plugs were transferred from colony margins to PDA amended with no fungicide, $2 \% \mathrm{NaCl}$, and $4 \% \mathrm{NaCl}$, with three replicate plates for each concentration. After 2 days, relative growth was determined. The experiment was conducted twice.

Mycelium intracellular glycerol accumulation assay. Because fludioxonil resistance has been associated with inhibition of the HOG-MAPK pathway and limitation of glycerol production, intracellular glycerol levels were determined in the presence and absence of fludioxonil for $\mathrm{S}$ and $\mathrm{HR}$ isolates. Mycelial hyphae were transferred on the tip of a toothpick from 1- to 2-week-old cultures to $50-\mathrm{ml}$ Falcon tubes containing $20 \mathrm{ml}$ potato dextrose broth. Three replicate tubes were used for each isolate and treatment. These liquid cultures were incubated at $22^{\circ} \mathrm{C}$ for $72 \mathrm{~h}$ and shaken at $100 \mathrm{rpm}$. At the end of this incubation period, fludioxonil was added to treatment tubes to a final concentration of $1 \mu \mathrm{g} / \mathrm{ml}$, and tubes were incubated for an additional $4 \mathrm{~h}$ at $22^{\circ} \mathrm{C}$ and shaken at $100 \mathrm{rpm}$. Mycelium was then washed with sterile water, vacuum filtered, and weighed. Mycelium was then placed in $1 \mathrm{ml}$ centrifuge tubes, and sterile water was added at a ratio of $0.1 \mathrm{~g}$ of mycelium per milliliter of water. After tissue was pulverized with an electric grinder, the mixture was centrifuged for $10 \mathrm{~min}$ at $12,000 \mathrm{rpm}$. Glycerol content in the supernatant was determined with the EnzyChrom Glycerol Assay Kit (BioAssay Systems, San Francisco, CA) according to manufacturer specifications.

Pathogenicity and fungicide sensitivity detached flower assays. To determine pathogenicity of isolates and field relevance of fludioxonil resistance, detached flower assays were performed based on a protocol previously developed for petunia flowers (Bennett 2019). Twenty-three 5.7-liter pots with commercially grown calibrachoa plants, cultivar 'MiniFamous Neo Royal Blue,' were kept in a climate-controlled greenhouse in Clemson, South Carolina, with heating and cooling set points at 22 and $27^{\circ} \mathrm{C}$, respectively, and retractable curtains providing $55 \%$ shade when external solar radiation exceeded $800 \mathrm{~W} / \mathrm{m}^{2}$. No fungicides or insecticides were applied to plants or flowers for a month before experiments began. To ensure use of flowers at a similar growth stage and to decrease the likelihood of flower senescence during experimental trials, all open flowers were removed from plants before each trial. One to three days later, newly opened flowers were collected and placed in 7.6- $\mathrm{cm}$ floral tubes $(1.27 \mathrm{~cm}$ diameter opening) filled to the brim with water. Treatment flowers were sprayed with fludioxonil (Scholar; Syngenta) at $1.5 \mathrm{mg}$ a.i./ml, iprodione (Rovral; Bayer CropScience) at $1.5 \mathrm{mg}$ a.i./ml, and chlorothalonil (Daconil; Syngenta) at $1.7 \mathrm{mg}$ a.i./ml. These dosages represent the field rates recommended for gray mold control according to the labels of products registered for ornamental use: Medallion (fludioxonil; Syngenta), Chipco (Iprodione; Bayer), and Daconil (chlorothalonil; Syngenta). Sterile water was applied to untreated control flowers. Sprayed flowers in tubes were left overnight in a sterile hood, then placed in plastic boxes measuring $16.7 \times 46.2 \times 30.48 \mathrm{~cm}(\mathrm{~L} \times \mathrm{W} \times \mathrm{D}$; Hefty, Reynolds Consumer Products, Lake Forest, IL) filled with sterilized sand to a depth of
$15 \mathrm{~cm}$. A total of $600 \mathrm{ml}$ of water was added to the sand in each box just before the experiment to produce a humid chamber with approximately $100 \%$ relative humidity. Three floral tubes containing flowers were inserted into sand to a depth of approximately $3 \mathrm{~cm}$, and three sprays (approximately $0.4 \mathrm{ml}$ ) of 2 to $3 \times 10^{5}$ spores/ $\mathrm{ml}$ suspension were applied to each flower with a fine spray hand mister. Boxes were then sealed, randomized, and incubated in a growth chamber with temperature set to $22^{\circ} \mathrm{C}$ with $12 \mathrm{~h}$ light and dark cycles. Flower infection incidence was rated based on the presence or absence of disease symptoms, results were read after 2 days, and the entire experiment was performed twice.

Fitness assessment. Fitness of HR isolates was assessed through mycelial growth and sporulation in vitro. In vitro mycelial growth was analyzed for HR and S isolates on both PDA and MEA media. Two perpendicular colony diameter measurements were taken for each plate after 2 days of growth. Three replicate plates were used for each isolate and medium type, and the experiment was conducted twice. One experimental replicate of S isolate FLOR5 had abnormally low growth and was therefore replaced with a replicate performed at a later date.

For in vitro sporulation trials, colonies were grown at $22^{\circ} \mathrm{C}$ in $12 \mathrm{~h}$ light/dark cycles for 30 days, then spores were counted. To determine spore counts, all mycelium was scraped from the surface of plates, washed, and vortexed with $2 \mathrm{ml}$ of water. Then $10 \mu \mathrm{l}$ of spore suspension was removed and spores counted twice with a hemacytometer. Spore counts were performed for all isolates except isolate HP9, which did not sporulate in trials.

To investigate the ability of isolates to sporulate on calibrachoa flowers, untreated flowers were inoculated with $0.4 \mathrm{ml}$ of 2 to $3 \times$ $10^{5}$ spores $/ \mathrm{ml}$ suspension in humid chambers. After 3 days of incubation, flowers were removed from humid chambers and placed in Petri dishes at $22^{\circ} \mathrm{C}$ in a light/dark incubator to decrease humidity and allow spore production. After 15 days, samples were examined for spore production under a microscope.

Data analysis. Statistical models were developed to determine the relationships between the responses of mycelial growth, osmotic sensitivity, glycerol concentration, flower infection rating, and fitness parameters with the factors of experimental replicate, medium type, isolate, resistance, and their combinations. All models were full factorial general linear regression models. The data from two independent experiments for each experimental response were combined, and significant differences determined via analysis of variance. For mean separations, least squares mean differences Student's $t$ tests were used. All statistical analyses were performed with $\alpha=0.05$ and run in JMP Pro version 14 (SAS Institute Inc., Cary, NC).

\section{RESULTS}

Characterization of sensitivity to fludioxonil and iprodione. $E C_{50}$ values for mycelial growth and germination. Both isolates exhibited high resistance to fludioxonil and iprodione in vitro, with spore germination and mycelial growth $\mathrm{EC}_{50}$ values $>100 \mu \mathrm{g} / \mathrm{ml}$. On both MEA and PDA media, germination was not significantly inhibited by fludioxonil or iprodione $(P=0.8647)$. No significant effects or interactions were detected in statistical analysis of spore germination.

Mycelial growth of isolate 5.8.19 was not significantly inhibited by fludioxonil on either MEA $(P=0.1435)$ or PDA $(P=0.4615)$. Mycelial growth of isolate 5.10.19 was not significantly inhibited by fludioxonil on PDA $(P=0.3031)$. However, it was inhibited on MEA $(P<0.0001)$, with an average relative growth of $73 \%$. Isolate 5.8.19 mycelial growth was inhibited by iprodione on PDA $(P<$ $0.0001)$, with a relative growth of $91 \%$. However, on MEA $(P=$ 0.0066), isolate 5.8.19 grew more on iprodione than on the control. Isolate 5.10.19 mycelial growth was inhibited by iprodione on MEA $(P<0.0001)$, with a relative growth of $78 \%$ but not on PDA $(P=$ 0.1738). Significant statistical effects of isolate $(P<0.0001)$, 
medium $(P=0.0023)$, and treatment $(P=0.0491)$ factors on the colony diameter response and significant interactions between isolate by medium by treatment $(P<0.0001)$; isolate by treatment $(P<0.0001)$; and medium by treatment $(P=0.0226)$ were observed.

Stability of resistance. High resistance to both fludioxonil and iprodione was stable after 22 transfers on unamended MEA. On the last transfer, both HR isolates grew between 90 and $110 \%$ relative to the control on media amended with $100 \mu \mathrm{g} / \mathrm{ml}$ fludioxonil and $100 \mu \mathrm{g} / \mathrm{ml}$ iprodione, retaining their $\mathrm{EC}_{50}>100 \mu \mathrm{g} / \mathrm{ml}$. EC $\mathrm{E}_{50}$ values $>100 \mu \mathrm{g} / \mathrm{ml}$ were observed in isolates transferred on unamended MEA for 3 months and for isolates stored in filter paper cultures in the $-20^{\circ} \mathrm{C}$ freezer for 3 months.

Bos-1 and mrrl gene sequences. Sequence data, protein sequence. Mutations in the Botrytis two-component osmosensing histidine-kinase gene (Bos-1) have been shown to confer high resistance to both fludioxonil and iprodione in previous studies (Ren et al. 2016; Sang et al. 2018). The Bos-1 gene was sequenced for both HR isolates to detect potential fludioxonil resistancecausing mutations. The regions sequenced were 4,492 bp long and included the entire coding sequence of the gene (accession nos. MT497335 and MT497336). The sequences for both isolates contained previously reported iprodione resistance mutations F127S (ATC $\rightarrow$ AAC) and I365N (TTT $\rightarrow$ TCT). However, isolate 5.8.19 additionally contained the mutation L267V between HAMP domains 1 and 2 (Table 2).

A variety of mutations in the multidrug resistance regulator 1 gene ( $m r r l)$ can result in low to moderate fludioxonil resistance but not cross-resistance to iprodione (Table 1). To determine whether these mutations were present, the majority of the $\mathrm{mrrl}$ coding region was sequenced for HR isolates 5.8.19 and 5.10.19. The resulting nucleotide sequences were 2,400 bp long and were identical for both isolates (accession nos. MT497337 and MT497338). These sequences were $100 \%$ identical to previously characterized $\mathrm{mrrl}$ sequences of a representative group $\mathrm{S}$ isolate from Germany, accession no. JX266765 (Leroch et al. 2012), and contained the 3-bp deletion $\Delta \mathrm{L} 497$, associated with the MDR1h phenotype (Table 1).

Osmotic sensitivity. Because resistance associated with the MAPK pathway generally confers increased osmotic sensitivity, the sensitivity of $\mathrm{HR}$ isolates to salt stress was investigated on 2 and $4 \%$ $\mathrm{NaCl}$ media. Growth of both HR isolates was significantly inhibited compared with sensitive isolates by $2 \% \mathrm{NaCl}$ on both MEA $(P<$ $0.0001)$ and PDA $(P<0.0001)$ and completely inhibited by $4 \%$ $\mathrm{NaCl}$ on both MEA and PDA (Fig. 1). Resistant isolates were consistently inhibited on both media, although some differences between media were observed for sensitive isolates. (Fig. 1). Significant effects of experimental replicate $(P=0.0328)$, isolate $(P<0.0001)$, medium $(P<0.0001)$, and treatment $(P<0.0001)$ on the relative growth response were detected. Additionally, significant interactions were detected between experimental replicate and isolate $(P<0.0001)$; experimental replicate and medium $(P=$ $0.0011)$; isolate and medium $(P<0.0001)$; experimental replicate, isolate, and medium $(P=0.0027)$; and isolate and treatment $(P<$ $0.0001)$. The significant effect of experimental replicate $(P=$ 0.0328) was detected because sensitive isolate FLOR5 grew inconsistently between replications on MEA. However, its growth was consistently significantly greater than that of resistant isolates, so replications were still combined.

Intracellular glycerol accumulation. Because fludioxonil resistance associated with the MAPK pathway typically prevents accumulation of intracellular glycerol in the presence of fungicide, glycerol content of HR and S isolates was analyzed in the presence and absence of fludioxonil. In the absence of fludioxonil, all isolates had low average glycerol concentrations, ranging between 0.05 and $0.13 \mathrm{mM}$. Neither resistant isolate significantly increased production of glycerol in the presence of fludioxonil $(P=0.3658)$. However, all three sensitive isolates significantly increased glycerol production in the presence of fludioxonil $(P<0.0001)$ (Fig. 2). Significant effects of isolate $(P<0.0001)$, treatment $(P<0.0001)$,

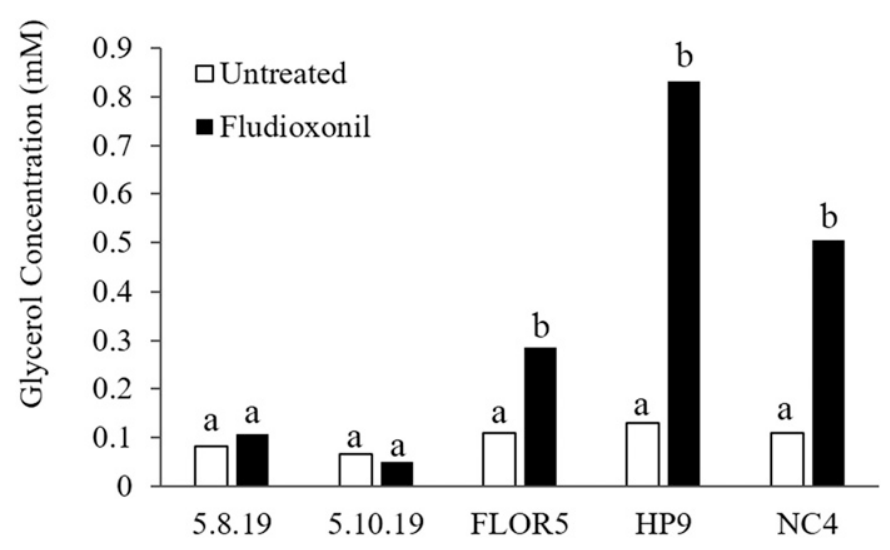

Fig. 2. Glycerol concentration in mycelium of isolates treated and untreated with fludioxonil, with statistical comparisons across all isolates and treatments. Letters designating statistical differences compare glycerol concentrations within but not between isolates.
A

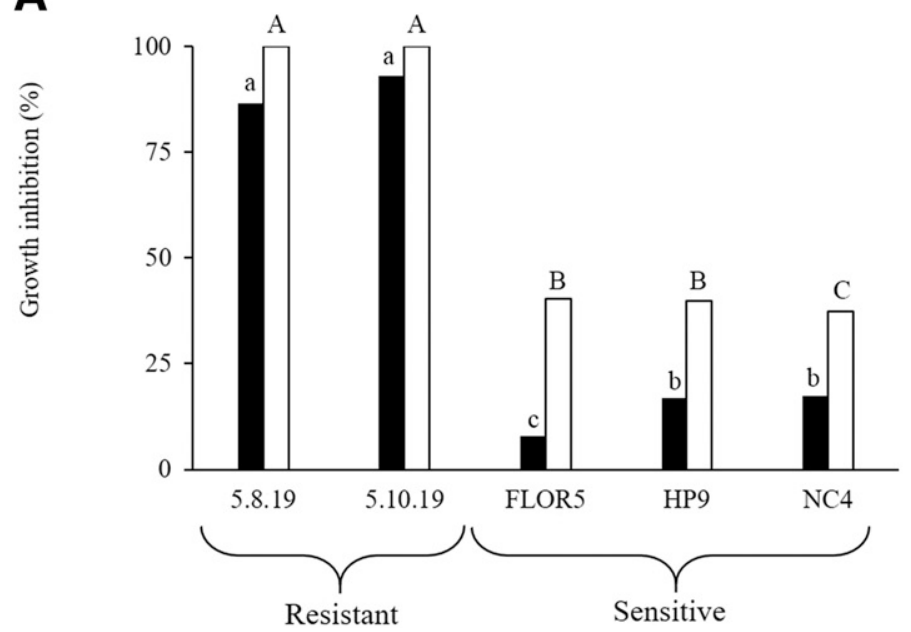

B

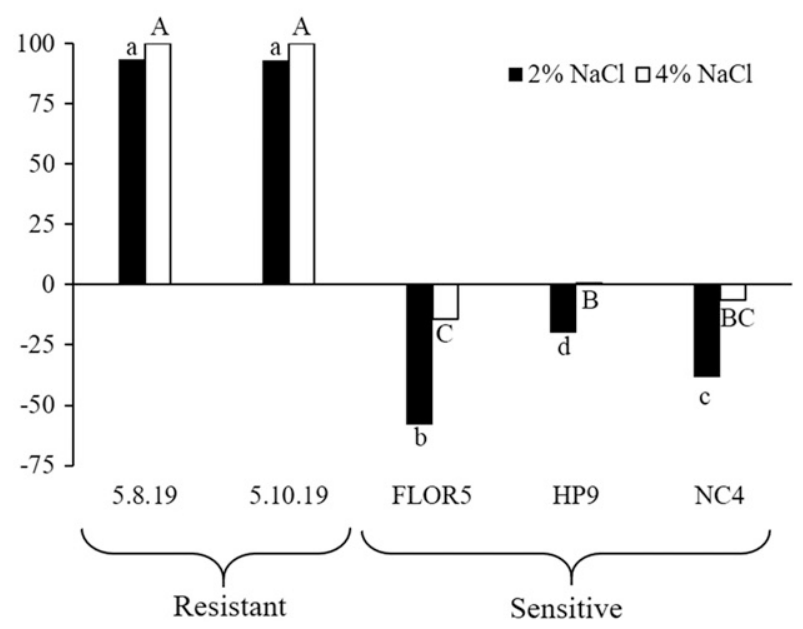

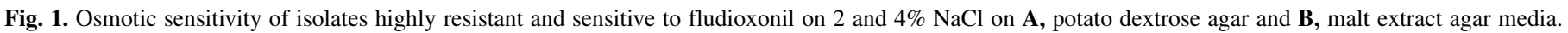
Statistical comparisons were performed separately for 2 and $4 \%$ salt treatments, as indicated by upper and lowercase letters. 
and experimental replicate $(P=0.0003)$ factors were observed on the response of glycerol concentration. Additionally, significant interactions between isolate and treatment $(P<0.0001)$; isolate and experimental replicate $(P=0.0004)$; treatment and experimental replicate $(P=0.0108)$; and isolate, treatment, and experimental replicate $(P=0.0171)$ were detected. The significant effect of experimental replicate $(P=0.00027)$ was detected because of variation in glycerol accumulation between replicates of the $S$ isolate HP9 treated with fludioxonil. However, fludioxonil-treated replications were always significantly greater than the untreated replications for this isolate, so replications were still combined for analyses.

Pathogenicity and fungicide resistance ex vivo on detached flowers. To assess practical relevance of high fludioxonil resistance, detached flower assays were performed, and isolates were exposed to recommended label rates of fludioxonil and iprodione. No fungal growth or symptoms were observed on any uninoculated flowers. On flowers not treated with fungicide, the percentage of infected flowers ranged from 67 to $100 \%$, with an average of $94.5 \%$. No isolate was consistently less pathogenic than other isolates. After treatment with label rates of fludioxonil and iprodione, sensitive isolate FLOR5 did not form any disease symptoms on flowers. Highly resistant isolates 5.8.19 and 5.10.19 caused significantly more or the same amount of disease as on flowers not treated with fungicide $(P=0.00238)$. Chlorothalonil generally reduced disease incidence significantly compared with the watertreated control or the resistant isolates treated with fungicide, though not as dramatically as fludioxonil and iprodione. Exceptions were a single repetition of isolate 5.8.19 treated with chlorothalonil that did not significantly reduce incidence and individual replicates of isolates 5.8.19 and FLOR5 that chlorothalonil inhibited to the same extent as fludioxonil and iprodione $(P=0.1798)$. (Fig. 3, Supplementary Fig. S1). Significant effects of the factors treatment $(P<0.0001)$ and isolate $(P<0.0001)$ on presence or absence of infection symptoms were detected, as well as interactions between experimental replicate and isolate $(P=0.0147)$; treatment and isolate $(P<0.0001)$; and experimental replicate, treatment, and isolate $(P=0.0024)$.

Fitness of isolates resistant and sensitive to fludioxonil. To determine whether high resistance to fludioxonil and iprodione resulted in fitness penalties, growth rate and spore production were analyzed for $\mathrm{S}$ and $\mathrm{HR}$ isolates. In both experimental replicates, HR isolates grew significantly more slowly than sensitive isolates on both MEA $(P<0.0001)$ and PDA $(P<0.0001)$ after 2 days of growth. Isolate 5.8.19 had significantly larger colony diameter than 5.10.19 on MEA $(P<0.0001)$, but the difference between the two

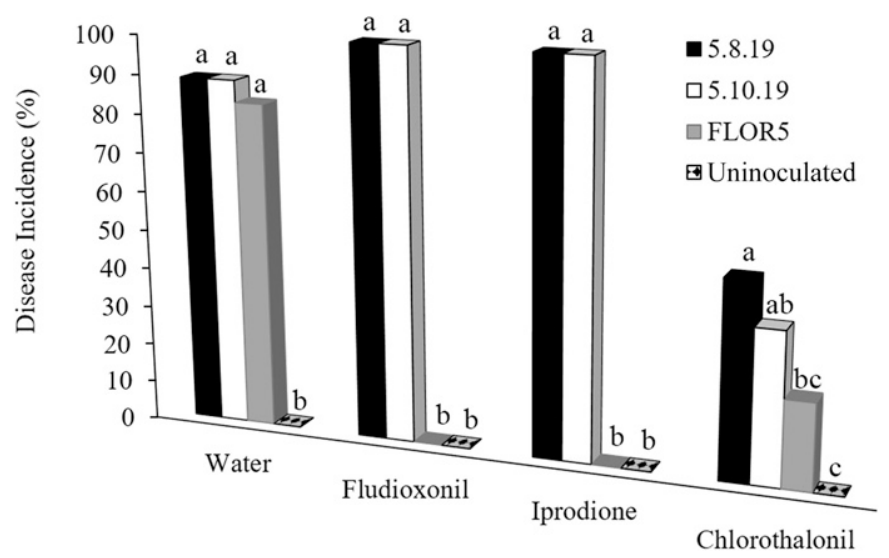

Fig. 3. Disease incidence on uninoculated flowers and flowers inoculated with highly resistant isolates 5.8.19, 5.10.19, and sensitive isolate FLOR5. Letters designating statistical differences compare flower disease incidence within but not between treatments. isolates was insignificant on PDA $(P=0.0534)$, although isolate 5.8.19's average diameter was numerically larger for both media (Table 3). Significant effects of the factors of experimental replicate $(P<0.0001)$, isolate $(P<0.0001)$, and medium $(P<0.0001)$ on colony diameter were detected, as were significant interactions between experimental replicate and isolate $(P<0.0001)$; isolate and medium $(P<0.0001)$; and experimental replicate, isolate, and medium $(P=0.370)$. The significant effect of experimental replicate $(P<0.0001)$ was detected through variations between $\mathrm{S}$ isolate diameters between replications. However, on both media types, the sensitive isolates consistently grew significantly more than resistant isolates, so replications were combined.

$\mathrm{HR}$ and $\mathrm{S}$ isolates were able to produce spores both in vitro and ex vivo on detached flowers. In vitro, sensitive isolates $\mathrm{NC4}$ and FLOR5 produced significantly more spores than HR isolates 5.8.19 and 5.10 .19 on both media types $(P<0.0001)$. No significant difference was detected in sporulation between isolates 5.8.19 and 5.10.19 $(P=0.8563)$ or between isolates NC4 and FLOR5 $(P=$ 0.1543 ) on either medium. Significant effects of the factor of isolate $(P<0.0001)$ on spore count were detected, as were interactions between assay and medium $(P=0.0003)$ and assay, isolate, and medium $(P=0.0072)$.

\section{DISCUSSION}

Although MDR-based low and moderate resistance to fludioxonil have occurred in fields for years, detection of HR B. cinerea isolates is unusual and potentially concerning. Fludioxonil has had an unprecedented history of limited resistance development and is often the primary single-site inhibitor used to control emergency outbreaks in commercial production of strawberries and other crops (Kilani and Fillinger 2016). However, this article is the fourth report of high resistance to fludioxonil in greenhouse production worldwide in 5 years (Ren et al. 2016; Sang et al. 2018; Zhou et al. 2020) (Table 1).

High resistance to fludioxonil has been consistently linked to increased osmotic sensitivity, lack of glycerol accumulation in the presence of fludioxonil, and (in most cases) mutations in the HAMP domains of the Bos- 1 gene associated with iprodione or fludioxonil resistance (Fillinger et al. 2012; Ren et al. 2016; Sang et al. 2018; Zhou et al. 2020). Our isolates followed similar trends, lacking fludioxonil-induced glycerol accumulation and exhibiting increased osmotic sensitivity. Both HR isolates exhibited iprodione resistance ex vivo and in vitro and contained the documented dicarboximide resistance mutations F127S and I365N (FernándezOrtuño et al. 2015; Grabke et al. 2014; Ma et al. 2007). Isolate 5.8.19 also contained the mutation L267V between HAMP domains 1 and 2, near the mutations $\mathrm{G} 262 \mathrm{~S}$ and G265D, associated with fludioxonil resistance by Ren et al. (2016) in greenhouse isolates. A knockout and molecular modeling study revealed that the nearby

TABLE 3. Fitness components of isolates sensitive and highly resistant to fludioxonily

\begin{tabular}{|c|c|c|c|c|c|c|}
\hline \multirow[b]{3}{*}{ Isolates } & & & \multicolumn{4}{|c|}{ Fitness components ${ }^{\mathrm{z}}$} \\
\hline & \multicolumn{2}{|c|}{ Phenotype } & \multicolumn{2}{|c|}{$\begin{array}{l}\text { Mycelial growth } \\
\qquad(\mathrm{mm})\end{array}$} & \multicolumn{2}{|c|}{$\begin{array}{c}\text { Spores } \times \\
10^{4} \text { per } \mathrm{ml}\end{array}$} \\
\hline & Fludioxonil & Iprodione & MEA & PDA & MEA & PDA \\
\hline 5.8 .19 & $\mathrm{HR}$ & HR & $15.4 \mathrm{~b}$ & $18.3 \mathrm{~B}$ & $0.5 \mathrm{~B}$ & $15.1 \mathrm{BC}$ \\
\hline 5.10 .19 & $\mathrm{HR}$ & HR & $11.9 \mathrm{a}$ & $16.6 \mathrm{~A}$ & $0.4 \mathrm{~B}$ & $3.0 \mathrm{C}$ \\
\hline FLOR5 & $\mathrm{S}$ & $\mathrm{S}$ & $29.1 \mathrm{c}$ & $38.1 \mathrm{C}$ & $123 \mathrm{~A}$ & $88.5 \mathrm{AB}$ \\
\hline $\mathrm{NC} 4$ & $\mathrm{~S}$ & $\mathrm{~S}$ & $23.0 \mathrm{~d}$ & $43.9 \mathrm{D}$ & $175 \mathrm{~A}$ & $135 \mathrm{~A}$ \\
\hline HP9 & $\mathrm{S}$ & $\mathrm{S}$ & $24.4 \mathrm{~d}$ & $38.9 \mathrm{C}$ & n.d. & n.d. \\
\hline
\end{tabular}

y HR, highly resistant; MEA, malt extract agar; n.d., data not determined in this study; PDA, potato dextrose agar; $\mathrm{S}$, sensitive.

z Statistical comparisons were performed separately for each medium, as indicated by uppercase and lowercase letters. 
G278D mutation in the Bos- 1 gene of a lab mutant conferred high fludioxonil and iprodione resistance and osmotic sensitivity (Fillinger et al. 2012) (Table 1).

Isolate 5.10.19 did not contain mutations other than F127S and I365N in the Bos- 1 gene. HR to fludioxonil and osmotic sensitivity in the absence of Bos-1 mutations has been reported before for a laboratory mutant but never for a greenhouse or field isolate (Zhou et al. 2020). Other genes such as Sakl (Segmüller et al. 2007), BcOS4 (Yang et al. 2012), bos5 (Yan et al. 2010), and BRRG-1 (Yan et al. 2011), associated with the HOG1 MAPK pathway in $B$. cinerea, have been reported, but knockouts of these genes resulted in unchanged or increased sensitivity to fludioxonil (Segmüller et al. 2007; Yan et al. 2011, 2010; Yang et al. 2012), and isolate 5.10.19 exhibits HR to fludioxonil. Previous literature has suggested that Bos- 1 regulates the gene $S a k-1$ but that a separate pathway is responsible for dicarboximide and phenylpyrrole resistance (Liu et al. 2008). It is possible that malfunction of a gene in this separate pathway may be responsible for resistance in isolate 5.10.19 (Liu et al. 2008).

Although HR isolates 5.8.19 and 5.10.19 exhibited the 3-bp deletion $\Delta \mathrm{L} / \mathrm{V} 497$ in the gene $m r r l$, conferring the MDR1h phenotype, it is unlikely that the MDR1h phenotype is responsible for the fludioxonil $\mathrm{HR}$ observed. The highest fludioxonil $\mathrm{EC}_{50}$ values for $B$. cinerea isolates with the MDR1h phenotype are typically about 3.1 , and $\mathrm{HR}\left(\mathrm{EC}_{50}>5 \mu \mathrm{g} / \mathrm{ml}\right)$ to fludioxonil caused by atrB efflux has never been reported for $B$. cinerea (FernándezOrtuño et al. 2015; Fillinger et al. 2012; Hu et al. 2019) (Table 1). Also, our HR isolates exhibited changes in glycerol accumulation and osmotic sensitivity indicative of HOG1 MAPK interruption. Osmotic sensitivity has been reported for MDR1h isolates, but inhibition on $4 \% \mathrm{NaCl}$ PDA media was $<50 \%$ compared with the complete inhibition observed for our HR isolates (FernándezOrtuño et al. 2015). Additionally, mycelial growth (Supplementary Fig. S2) and sporulation of our HR isolates were significantly less than those of sensitive isolates, and the literature reports that MDR1h isolates do not significantly differ from sensitive isolates in these traits when grown at $22^{\circ} \mathrm{C}$ (Fernández-Ortuño et al. 2015). It is also unlikely that mycelial growth and osmotic fitness penalties are caused by resistance to other chemical classes of fungicides. Chen et al. (2016) previously showed that mycelial growth of $B$. cinerea isolates with resistance to five or six chemical classes at the same time was not significantly different from that of fully sensitive controls. Additionally, isolates with resistance to five or six chemical classes were only slightly more sensitive to osmotic pressure than fully sensitive isolates at $22^{\circ} \mathrm{C}$ (Chen et al. 2016).

Although recent reports highlight the presence of highly resistant fludioxonil isolates in China, and this study shows that HR isolates are also present in the United States, their importance to commercial production is uncertain (Ren et al. 2016; Sang et al. 2018; Zhou et al. 2020). HR isolates consistently exhibit lower growth rates, sporulation, and greater osmotic sensitivity than sensitive isolates. Also, HR isolates have never been reported outside greenhouse conditions, where high humidity and plant concentration provide the ideal atmosphere for resistance development and spread. Even within greenhouses, outbreaks of HR isolates appear to be well contained, making up small percentages of the population and not resulting in complete loss of fludioxonil efficacy in the locations where resistance has been reported (Ren et al. 2016). Therefore, fitness penalties may prevent these isolates from causing imminent widespread crop loss through lack of efficacy. However, these findings indicate the need to use fludioxonil with caution and use resistance management techniques.

\section{ACKNOWLEDGMENTS}

We thank Melissa Muñoz and William Bridges for their assistance with statistical analysis, and P. K. Bryson and Sydney Lykins (Clemson University) for technical support.

\section{LITERATURE CITED}

Avenot, H. F., and Michailides, T. J. 2015. Detection of isolates of Alternaria alternata with multiple-resistance to fludioxonil, cyprodinil, boscalid and pyraclostrobin in California pistachio orchards. Crop Prot. 78:214-221.

Bennett, K. 2019. The effect of calcium on Botrytis blight of petunia flowers. All Theses 3108. https://tigerprints.clemson.edu/all_theses/3108

Chen, S. N., Luo, C. X., Hu, M. J., and Schnabel, G. 2016. Fitness and competitive ability of Botrytis cinerea isolates with resistance to multiple chemical classes of fungicides. Phytopathology 106:997-1005.

Chi, M.-H., Park, S.-Y., and Lee, Y.-H. 2009. A quick and safe method for fungal DNA extraction. Plant Pathol. J. 25:108-111.

Cosseboom, S. D., Ivors, K. L., Schnabel, G., Bryson, P. K., and Holmes, G. J. 2019. Within-season shift in fungicide resistance profiles of Botrytis cinerea in California strawberry fields. Plant Dis. 103:59-64.

Fernández-Ortuño, D., Grabke, A., Bryson, P. K., Amiri, A., Peres, N. A., and Schnabel, G. 2014. Fungicide resistance profiles in Botrytis cinerea from strawberry fields of seven southern U.S. states. Plant Dis. 98:825-833.

Fernández-Ortuño, D., Grabke, A., Li, X., and Schnabel, G. 2015. Independent emergence of resistance to seven chemical classes of fungicides in Botrytis cinerea. Phytopathology 105:424-432.

Fillinger, S., Ajouz, S., Nicot, P. C., Leroux, P., and Bardin, M. 2012. Functional and structural comparison of pyrrolnitrin- and iprodione-induced modifications in the class III histidine-kinase bos1 of Botrytis cinerea. PLoS One 7:e42520.

Förster, H., Driever, G. F., Thompson, D. C., and Adaskaveg, J. E. 2007. Postharvest decay management for stone fruit crops in California using the "reduced-risk" fungicides fludioxonil and fenhexamid. Plant Dis. 91: 209-215.

Furukawa, K., Randhawa, A., Kaur, H., Mondal, A. K., and Hohmann, S. 2012. Fungal fludioxonil sensitivity is diminished by a constitutively active form of the group III histidine kinase. FEBS Lett. 586:2417-2422.

Grabke, A., Fernández-Ortuño, D., Amiri, A., Li, X., Peres, N. A., Smith, P., et al. 2014. Characterization of iprodione resistance in Botrytis cinerea from strawberry and blackberry. Phytopathology 104:396-402.

Hahn, M. 2014. The rising threat of fungicide resistance in plant pathogenic fungi: Botrytis as a case study. J. Chem. Biol. 7:133-141.

Hu, M., Cosseboom, S., and Schnabel, G. 2019. atrB-associated fludioxonil resistance in Botrytis fragariae not linked to mutations in transcription factor $m r r l$. Phytopathology 109:839-846.

Kilani, J., and Fillinger, S. 2016. Phenylpyrroles: 30 years, two molecules and (nearly) no resistance. Front. Microbiol. 7:2014.

Kim, J.-O., Shin, J.-H., Gumilang, A., Chung, K., Choi, K. Y., and Kim, K. S. 2016. Effectiveness of different classes of fungicides on Botrytis cinerea causing gray mold on fruit and vegetables. Plant Pathol. J. 32:570-574.

Kretschmer, M., Leroch, M., Mosbach, A., Walker, A.-S., Fillinger, S., Mernke, D., et al. 2009. Fungicide-driven evolution and molecular basis of multidrug resistance in field populations of the grey mould fungus Botrytis cinerea ed. Alex Andrianopoulos. PLoS Pathog 5:e1000696.

Kumar, S., Stecher, G., and Tamura, K. 2016. MEGA7: Molecular Evolutionary Genetics Analysis version 7.0 for bigger datasets. Mol. Biol. Evol. 33:1870-1874.

Leroch, M., Kretschmer, M., and Hahn, M. 2011. Fungicide resistance phenotypes of Botrytis cinerea isolates from commercial vineyards in south west Germany: fungicide resistance of $B$. cinerea isolates from vineyards. J. Phytopathol. 159:63-65.

Leroch, M., Plesken, C., Weber, R. W. S., Kauff, F., Scalliet, G., and Hahn, M. 2012. Gray mold populations in German strawberry fields are resistant to multiple fungicides and dominated by a novel clade closely related to Botrytis cinerea. Appl. Environ. Microbiol. 79:159-167.

Leroux, P. 1996. Recent developments in the mode of action of fungicides. Pestic. Sci. 47:191-197.

Lew, R. R. 2010. Turgor and net ion flux responses to activation of the osmotic MAP kinase cascade by fludioxonil in the filamentous fungus Neurospora crassa. Fungal Genet. Biol. 47:721-726.

Li, X., Fernández-Ortuño, D., Grabke, A., and Schnabel, G. 2014. Resistance to fludioxonil in Botrytis cinerea isolates from blackberry and strawberry. Phytopathology 104:724-732.

Liu, W., Leroux, P., and Fillinger, S. 2008. The HOG1-like MAP kinase Sak1 of Botrytis cinerea is negatively regulated by the upstream histidine kinase Bos1 and is not involved in dicarboximide- and phenylpyrrole-resistance. Fungal Genet. Biol. FG B. 45:1062-1074.

Ma, Z., Yan, L., Luo, Y., and Michailides, T. J. 2007. Sequence variation in the two-component histidine kinase gene of Botrytis cinerea associated with resistance to dicarboximide fungicides. Pestic. Biochem. Physiol. 88:300-306.

Malandrakis, A. A., Apostolidou, Z. A., Markoglou, A., and Flouri, F. 2015. Fitness and cross-resistance of Alternaria alternata field isolates with specific or multiple resistance to single site inhibitors and mancozeb. Eur. J. Plant Pathol. 142:489-499. 
Petit, A.-N., Vaillant-Gaveau, N., Walker, A.-S., Leroux, P., Baillieul, F., Panon, M.-L., Clément, C., and Florence, F. 2011. Effects of fludioxonil on Botrytis cinerea and on grapevine defense response. Phytopathol. Mediterr. 50:130-138.

Ren, W., Shao, W., Han, X., Zhou, M., and Chen, C. 2016. Molecular and biochemical characterization of laboratory and field mutants of Botrytis cinerea resistant to fludioxonil. Plant Dis. 100:1414-1423.

Rupp, S., Weber, R. W. S., Rieger, D., Detzel, P., and Hahn, M. 2017. Spread of Botrytis cinerea strains with multiple fungicide resistance in German horticulture. Front. Microbiol. 7:2075.

Sang, C., Ren, W., Wang, J., Xu, H., Zhang, Z., Zhou, M., et al. 2018. Detection and fitness comparison of target-based highly fludioxonil-resistant isolates of Botrytis cinerea from strawberry and cucumber in China. Pestic. Biochem. Physiol. 147:110-118.

Segmüller, N., Ellendorf, U., Tudzynski, B., and Tudzynski, P. 2007. BcSAK1, a stress-activated mitogen-activated protein kinase, is involved in vegetative differentiation and pathogenicity in Botrytis cinerea. Eukaryot. Cell 6:211-221.

Viaud, M., Fillinger, S., Liu, W., Polepalli, J. S., Le Pêcheur, P., Kunduru, A. R., et al. 2006. A class III histidine kinase acts as a novel virulence factor in Botrytis cinerea. Mol. Plant-Microbe Interact. 19:1042-1050.
Yan, L., Yang, Q., Jiang, J., Michailides, T. J., and Ma, Z. 2011. Involvement of a putative response regulator Brrg-1 in the regulation of sporulation, sensitivity to fungicides, and osmotic stress in Botrytis cinerea. Appl. Microbiol. Biotechnol. 90:215-226.

Yan, L., Yang, Q., Sundin, G. W., Li, H., and Ma, Z. 2010. The mitogen-activated protein kinase kinase BOS5 is involved in regulating vegetative differentiation and virulence in Botrytis cinerea. Fungal Genet. Biol. 47:753-760.

Yang, Q., Yan, L., Gu, Q., and Ma, Z. 2012. The mitogen-activated protein kinase kinase kinase $\mathrm{BcOs} 4$ is required for vegetative differentiation and pathogenicity in Botrytis cinerea. Appl. Microbiol. Biotechnol. 96: 481-492.

Zhang, Y., Lamm, R., Pillonel, C., Lam, S., and Xu, J.-R. 2002. Osmoregulation and fungicide resistance: the Neurospora crassa os-2 gene encodes a HOG1 mitogen-activated protein kinase homologue. Appl. Environ. Microbiol. 68:532-538.

Zhou, F., Hu, H.-Y., Song, Y.-L., Gao, Y.-Q., Liu, Q.-L., Song, P.-W., Chen, E.-Y., Yu, Y.-A., Li, D.-X., and Li, C.-W. 2020. Biological characteristics and molecular mechanism of fludioxonil resistance in Botrytis cinerea from Henan Province of China. Plant Dis. 104:1041-1047. 